and pulse remained normal and no trouble arose at the seat of inoculation.

The bacteriological investigations, preparations of vaccine, inoculations, and determinations of variation in opsonic index were performed by Dr. G. W. Ross, house physician to the case, at whose suggestion the inoculation treatment had been adopted.

Victoria-square, S.W.

\section{A CASE OF LUDWIG'S ANGINA FOLLOWING INFLUENZA.}

By C. Ashley ScotT LeGGat', M.D. Edin.

THE patient, a woman, aged 37 years, was first seen on Feb. 21st. She was suffering from tonsillitis of the follicular type usually associated with influenza and of moderate severity. The case ran a normal course and the patient was practically well on the 27 th. On March 15 th she again sent for me as she had a swelling on the right side of the neck which she thought was due to mumps. She said that she had been fairly well during the intervening fortnight but had not felt quite herself, and first felt pain in the glands of the right side of the neck at a dinner party on the night of the 13th. On the next morning there was a swelling under the right side of the lower jaw but when seen by me on the 15th there was no swelling of the parotid nor was there any thing to be seen inside the throat though the patien complained of great pain in swallowing. The temperature was normal but the pulse was rather rapid from the first. During the next few days the patient suffered a great deal of pain but remained in much the same con lition and on the $25 \mathrm{th}$ Mr. E. Venning saw her with me and advised the removal of a septic molar tooth thinking that it might be the source of mischief. No improvement followed, the puise increasing in frequency, and the temperature beginning to rise every afternoon to $100^{\circ}$ or $101^{\circ} \mathrm{F}$., so on the 29th Mr. C. A. Ballance saw the case with me. During this day the pain had been severe and the pulse was 140 and at times slightly irregular, and immediate operation was decided upon. One incision was carried along the anterior border of the right sterno-mastoid and ar other shorter one was made at the posterior border of the muscle. Scarcely any pus was fourd but all the cellular tissue was grey-black in colour and gangrenous. The glands, too, along the internal jugular vein were in a state of infective inflammation; some of these were removed. It was then discovered that a coagulum occupied the interior of the jugular vein from the base of the skull to the level of the thyroid cartilage. The vein was divided between two ligatures and the proximal part containing the coagulum was fixed to the skin margin. The patient made a rapid convalescence and in three weeks was able to leave for the seaside.

It is difficult to say whether the tonsil or the carious tooth was the source of the infection of the spreading cellulitis of the neck. Carious teeth or caries of the alveolar process are a well-recognised avenue through which infection of the type of Ludwig's angina may arise in the cellular tissue of the neck. On the other hand, there is no reason why such an infection may not spread from an inflamed tonsil, a condition which has been known to occur in cerrain malignant scarlatinal cases. In this case the septic mischief in the tooth had been going on for years and probably the supervention of influenzal tonsillitis on the top of this was the immediate cause of the cellulitis. A point of great interest in the case is the thrombosis of the jugular vein which is of great rarity in cases of septic cellulitis of the neck. To this cause may be ascribed the slow onset of symptoms and the absence of severe constitutional symptoms. The blocking of the venous channel was nature's effort to localise the inflammatory process.

Walton-place, S.W.

The Dentists Act-At Crediton, Devonshire, on June 14th, Mr. William Baker of that town was summoned for an offence under the Dentists Act of 1878 . Evidence showed that the defendant had a brass plate at his house inscribed "W. Baker, surgeon dentist, Limited." The defendant stated that he was a doctor of dental surgery of Chicago, America, and that he had never represented himself to be a registered dentist under the Act of 1878. He was fined $£ 5$ and costs. The prosecution was instituted by the British Dental Association.

\section{9. 解tirror}

\section{HOSPITAL PRACTICE, BRITISH AND FOREIGN.}

Nulla autem est alia pro certo noscendi via, nisi quamplurimas et morborum et dissectionum historias, tum aliorum tum proprias collectas habere, et inter se comparare.-MorgagNI De Sed. et Caus. Morb., lib. iv., Procemium.

\section{KING'S COLLEGE HOSPITAL.}

A CASE OF ABSCESS OF THE LUNG FOLLOWING GASTRIC ULCER ; RECOVERY.

(Under the care of Sir HUGH R. BeEvor.)

Fon the notes of the case we are indebted to Mr. H. R. Allingham, senior house physician.

The patient, a female, aged 20 years, a domestic servant, had suffered from anæmia with much dyspepsia and constipation during the past two years, occasionally vomiting. On Feb. 24th, 1905, she sought advice for pain in the left anterior axillary line at about the ninth rib. Phrsical examination of the chest and the abdomen was negative and a mixture containing bismuth was prescribed. On the evening of the 26th, after a full and injudicious meal, the patient was seized with very severe pain in the abdomen, screaming out; she had the pulse of collapse and cold extremities. Morphine was given in repeated doses. Pain was localised to the splenic region with general abdominal tenderness. Next morning the pulse had recovered much, her temperature was $100^{\circ} \mathrm{F}$., the abdomen was not distended, but there was no apparent movement on descent of the diaphragm. There were marked hypogastric tenderness and an appearance of menses. During the next two days her temperature rose slightly and leucocytosis was 14000 per cubic millimetre, and Mr. F. F. Burghard was called in consultation. It was considered that the patient needed watching in hospital and she was admitted into King's College Hospital on March 2nd, 1905.

On admission the patient looked very ill, with a drawn and anxious face. Her temperature was $99^{\circ} \cdot 2^{\circ}$ and her pulse was 120 , of small volume. She complained of severe pain in the abdomen, mostly referred to the left iliac region. On examination the abdomen was slightly but uniformly distended there was rigidity of the muscles of the abdominal wall, and the abdomen did not move on respiration. There was great tenderness, more marked in the left iliac region. There were slight dulness in each flank, and absence of liver dulness. Some vomiting occurred and constipation was absolute (the bowels not having acted for some days), in spite of the free use of enemata. Immediate operation was considered inadvisable on account of the length of time that had elapsed since the onset of the symptoms and the absence of symptoms localising the suppuration. The abdominal signs continued but did not increase in severity and the disten-ion did not become greater. The pain was as before and the pyrexia ranged from $100^{\circ}$ to $101^{\circ}$. By March 6th thoracic signs became evident; dulness was present on the left side from the base of the lung to the fourth rib in the axillary line and over the dull area there was loss of breath sounds, and vocal resonance and tactile fremitus. A blood count now showed a leucocytosis of 18,000 . On the 9 th exploration of the left chest withdrew two ounces of blood-stained serous fluid; the signs in the chest became more marked and the abdominal -igns less evident, thongh pain continued in the abdomen. The apex beat was throughout in the fourth space, just internal to the nipple line. After the 11th the pyrexia steadily rose day by day with a feeble, rapid pulse (112), the respirations being 36 , until on the $16 \mathrm{th}$ the temperature reached $104.4^{\circ}$, accompanied by a lo ucocytosis of 32,600 to the cubic millimetre. The pain became severe and was localised in the left side of the chest and the left shoulder. The physical signs were as before except that the mobility of the abdomen was improved. There was no cough or sputum at this stage. A second exploration withdrew a small quantity of blood-stained serous fluid containing a few cells and sterile on culture. An $\mathrm{x}$ ray photograph showed a slight depre-sion and lattening of the left dome of the diaphragm and the area above the diaphragm 
showed a little opacity on the left side, as of a pleural effusion. The patient became drowsy and apathetic, only occasionally crying out with pain. By the 18 th over the dull area tubular breathing and bronchophony were present from the third to the eighth space on the left side, and below the eighth interspace there were signs of fluid effusion as before. During the next few days her general condition became worse, a chronic deafness became more complete, and the pain in the left shoulder was severe, her temperature varying betwreen $102^{\circ}$ and $104.4^{\circ}$. Cough appeared on the evening of March 22nd and became frequent and distressing, but there was no expectoration. The pulse was feeble (140) and the respirations were 40. At last, on March 23rd, in the early morning, the patient suddenly brought up, by combined coughing and vomiting, over a pint of fluid. This was chiefly foul pus, with some stomach contents intermixed. At the same time the temperature fell from $102^{\circ}$ to $97.4^{\circ}$ and the patient was collapsed, with cold sweat, thready pulse (132), and respirations 52 to the minute. Stimulants were freely used and five minims of solution of strychnine were injected hypodermically every four hours. During the next few days the patient continued to cough up foul pus and this did not end for nearly eight days after the rupture of the abscess. The cough was frequent and distressing and great effort produced only slight expectoration. Pain on being moved was acute. On the 25th (two days after rupture of the abscess) signs of pneumonic consolidation appeared at the right base, with pleural frictions, and great pain was felt in the right side. Her general condition was very bad and stimulants were freely administered, combined henceforth with large doses of tincture of perchloride of iron. In view of apparent inability to cough up the pus, \&c., emesis was induced with 30 grains of sulphate of zinc, but the result was not satisfactory. By the 29th in very slow stages the patient's condition had improved; the pyrexia, though very irregular, was less; and the condition of the lungs had improved, the right side resolving first. Cough continued very troublesome but expectoration became gradually merely bronchial mucus. Improvement slowly but steadily followed, only interrupted by a thrombosis of the left femoral vein which showed itself in pain and slight swelling of the limb and engorgement of the superficial veins of the leg and the thigh. The temperature did not become normal until so late as May 1st and it has continued so. At first during convalescence the heart's apex moved to the left and there were no normal breath sounds in the left lower lobe. The progress to normal sounds and rapidity of recovery of expansion of the left lung were more rapid than in cases of ordinary pleurisy. The measurement of the left chest is one and a quarter inches less than the right chest. The patient left the hospital practically quite well.

Remarks by Sir HUGH BEEVOR.-In the early days of this illness the symptoms pointed to a subdiaphragmatic abscess as much as a lung abscess, the diaphragm being evidently the site of inflammation. When the Roentgen rays localised the extension of the suppuration as being above the diaphragm any operation was precluded by the presence of serous effusion in the left pleura. In such conditions pneumothorax might have been expected to arise and cause more evil than any benefit to be gained by opening the abscess with such a complication added. But the chief interest in this case lies in the speed and thoroughness of recovery where the abscess was long in penetrating to a bronchus where secondary pneumonia developed in the other lung, and where the patient was of poor physique. In the face of unsatisfactory results reported in many cases operated upon for pulmonary abscess the experience of this patient seems worthy of notice.

\section{Middlesex County Lunatic Asylum-On} June 3rd Sir C. Francis Cory-Wright, Bart., D.L., formally opened the new asylum at Napsbury, near St. Albans, Herts. The buildings, which will accommodate about 1200, have been erected under the direction of the architect, Mr. Rowland Plumbe, and it is hoped that the needs of the county will be met for some years. The buildings have, however, been so designed as to allow of future development. It is almost needless to say that great attention has been paid to the sanitary arrangements of the asylum and that everything which could add to the wellbeing and comfort of the patients has been carefully thought out and supplied.

\section{Mttedial Sorietits.}

\section{EDINBURGH MEDICO-CHIRURGICAL SOCIETY.}

Extibition of Cases. - The Onset of Fear and the Onset of Pain in Cardiao Disturbanoe.-Acute Cerebro-spinal Fever and Intoxication.

A MeETING of this society was held on June 7th, Professor JoHN CHIENE, the President, being in the chair.

$\mathrm{Mr}$. ALEXANDER MILES showed four patients after operation for Acute Generalised Peritonitis resulting from Gangrenous Appendicitis. The patients were boys, aged respectively $9,13,16$, and 16 years, and were all in the wards of Leith Hospital at the same time during March and April of this year. The cases illustrated the benefit which resulted from washing out the abdominal cavity with saline solution in general peritonitis. Mr. Miles had operated on 45 cases of acute generalised peritonitis associated with gangrenous appendicitis; of these 25 ended fatally and 20 recovered and in all the latter the abdomen had been washed out. Mr. Miles also exhibited a Spleen removed for Traumatic Rupture. The man is now following his usual occupation.

Mr. F. M. CAIRD showed a man after Trephining for Extradural Hæmorrhage. The patient had been found lying unconscious at the foot of a stair. There was only a slight bleeding from the ear and the case seemed to be one of cerebral laceration. A subnormal temperature lasted for three days and suggested a suppurative condition of the brain. The size of the pupils varied from day to day. Seven days after the accident the muscles of the face on the left side commenced to twitch and this soon extended to the arm and leg of the same side. On trepbining over the fissure of Rolando on the right side a large, hard, cake-like blood clot, weighing four ounces, was found. Consciousness was regained almost immediately after the operation and though the ability to speak was at first poor it soon regained the normal amount. The patient recollected everything that had happened up to the moment of entering the passage leading to the stairs.

Mr. Alexis Thomson showed a man who had suffered from Tropical Abscess in the Right Lobe of the Liver which had been treated by syphon drainage after the method of Sir Patrick Manson. The exploring needle having shown the presence of pus a large trocar was passed into the cavity in the anterior axillary line and at the seventh interspace and the pus was allowed to escape. A large catheter was then introduced and fixed in, while a tube attached dipped below into a vessel containing boric solution. This form of syphon drainage was established for three weeks, allowing the escape of much thick brown pus. The result was absolutely satisfactory.

Dr. GEORGE A. GIBson showed a male patient suffering from Ophthalmoplegia Externa et Interna. The affection commenced five years previously in a slight drooping of the right eyelid and had progressively become worse. There was absolutely no movement in the right eye and in the left the superior oblique muscle had alone escaped. There was no alteration in the field of vision; all the cutaneous reflexes were exaggerated. Such cases had been described as superior tabes dorsalis. The disease consisted in a specific affection of the nuclei controlling the nerves of the eyeball.

Dr. GEORGE R. WILson read a paper entitled "The Onset of Fear and the Onset of Pain in Cardiac Disturbance." The fears referred to were paroxysmal and transient and for the most part nocturnal-such as fear of suicide, fear of disgrace, fear of poisoning someone, fear of mis-signing a cheque, and so on. These symptoms were common in patients suffering from abuse of alcohol and tobacco. The occasion of the dread was probably a transient bradycardia. None of these dreads were of long enough duration to constitute an obsession. With these might be compared the night-terrors of children, nightmare, and the sinking sensation, and the referred pains of cardiac disease. Head's explanation of referred pains was convincing so far as it related to the sympathetic and dorsal mechanism. The primary symptom in all the above experiences was a general and more or less acute sense of uneasiness. Then followed a quick conscious effort at localisation. Both these phases and the subsequent result-a pain or a fear-should be discussed 